\title{
A note on sampling baled grass silage for fungal propagules
}

\author{
M.O'Brien ${ }^{1,3,4}$, P.O'Kiely' ${ }^{1}$, P.D. Forristal' ${ }^{2}$ and H.T. Fuller ${ }^{3}$ \\ ${ }^{1}$ Teagasc, Grange Beef Research Centre, Dunsany, Co Meath, Ireland \\ ${ }^{2}$ Teagasc, Crops Research Centre, Oak Park, Co Carlow, Ireland \\ ${ }^{3} U C D$ School of Biology and Environmental Science, College of Life Sciences, \\ University College Dublin \\ Belfield, Dublin 4
}

(Received 9 August 2005; revised version 12 January 2006; accepted 12 April 2006)

\begin{abstract}
Ten bales of grass silage were cored at eight pre-determined positions and the mould and yeast propagules were enumerated. Both mould and yeast numbers varied greatly between and within individual bales. Yeast colony forming units (cfu) showed greater variability between (s.e. 1.44 $\log _{10} \mathrm{cfu} / \mathrm{g}$ ) than within bales (s.e. $0.53 \log _{10} \mathrm{cfu} / \mathrm{g}$ ). This variation between and within bales was statistically significant $(\mathrm{P}<0.05)$. When estimating the numbers of fungal propagules in bales that contain no visible mould or yeast growth, it is recommended that eight, or more, samples be taken per bale and these then composited to provide one representative sample of silage.
\end{abstract}

KEY WORDS: baled silage, sampling, mould, yeasts, propagules

\section{INTRODUCTION}

Fungal spores and possibly mycelia are ubiquitous in air, in soil, and on foliage when grass is being baled and wrapped for silage-making. Such fungal propagules can subsequently proliferate in the bales if the integrity of the airtight plastic stretch-film is damaged during wrapping, transport or storage. Fungal growth, in addition to causing quantitative and/or qualitative nutrient losses of silage, may expose livestock to respiratory allergies or infections. Additionally, mycotoxins may be present in the fungus-contaminated silage. O'Brien et al.

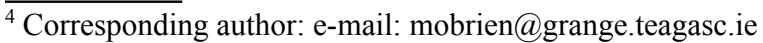


(2005) have described the widespread occurrence of the toxigenic mould Penicillium roqueforti on baled grass silage. Carry-over of mycotoxins into edible animal products such as milk or meat could be a possible route to human exposure (Veldman, 2003).

Information on the numbers and taxa of fungal propagules in baled grass silage is limited. Apart from the work of Skaar (1996), who quantified fungal propagules in mouldy and non-mouldy baled grass silage in Norway, there have been no substantial investigations on this topic. Additionally, information on the distribution of fungal propagules in individual silage bales is limited and accordingly appropriate procedures for microbiological sampling of this feedstuff have not been confirmed, although Seale et al. (1990) have identified important general practices to be used when enumerating bacteria and fungi in silage. Previous studies have used different methodologies when sampling bales for fungal propagules. For example, in determining the effects of additives on the quality of baled silage, Jonsson et al. (1990) drilled three cores to a depth of $0.4 \mathrm{~m}$ along each of four lines on the bale barrel to give 12 subsamples per bale; these subsamples were mixed prior to chemical and microbial analysis. In a mycological study on big bale grass silage in Norway, up to four samples were collected per bale at two different depths (surface sample and $0.3 \mathrm{~m}$ beneath the surface) and all were analysed separately for moulds and yeasts (Skaar, 1996). Neither of these two studies discussed the extent of fungal propagule variation among subsamples in bales.

As part of an on-going investigation of the mycobiota of baled grass silage in Ireland, bales free of visible mould or yeast growth were sampled in order to quantify the 'background' propagule load that could potentially grow and contaminate silage should air gain access through the plastic wrap prior to feedout. It was necessary to sample bales that were free of visible mould contamination because it has been demonstrated that propagule numbers in visually mouldy silages are considerably higher than in visually non-mouldy silages (Skaar, 1996; Auerbach et al., 1998). The objectives of the study were to 1. determine the size and variability of fungal propagule populations, both within individual bales and between bales in a collection that contained no visible mould, using a sampling protocol devised for that purpose, and 2. comment of the sampling stategy used and make recommendations for its improvement.

\section{MATERIAL AND METHODS}

In February 2003, at Oak Park Research Centre, Carlow, ten cylindrical-shaped 'round' bales $(1.2 \mathrm{~m} \times 1.2 \mathrm{~m}$, diameter $\times$ length $)$ of silage were chosen from 
a collection of 40 bales that had been harvested the previous summer from a single crop of perennial ryegrass and wilted for two days. The bales had been wrapped in four layers of black polythene stretch-film and stored outdoors on their curved sides (as in Figure 1) for approximately eight months prior to sampling. Access to a collection of 40 bales ensured that at least 10 bales would be available that were free of both damage to the plastic stretch-film and visible mould or yeast growth. Individual bales were sampled at eight positions (considered the maximum number of samples that could be processed comfortably on a daily basis) with a sharpened cylindrical steel corer (length, $22 \mathrm{~cm}$; inner and outer diameters 3.5 and $3.7 \mathrm{~cm}$, respectively) powered by an electrical drill. Sampling points were at 2.00, 4.00, 8.00 and $10.00 \mathrm{~h}$ clock positions on each side of the bale barrel, about $40 \mathrm{~cm}$ from each end (Figure 1). At each sampling position, cores were taken to a depth of about $20 \mathrm{~cm}$, based on the distribution of forage within bales as demonstrated by Forristal and O'Kiely (2003). Silage samples, each weighing between 60 and $70 \mathrm{~g}$, were aseptically transferred from each core to clean plastic bags from which the air was then expelled and the bags sealed. The corer was disinfected between samples using 99\% alcohol. Mould and yeast counts were determined in duplicate $30 \mathrm{~g}$ sub-samples from each sampling position using the spread-plate technique (Auerbach et al., 1998) and malt yeast extract sucrose agar

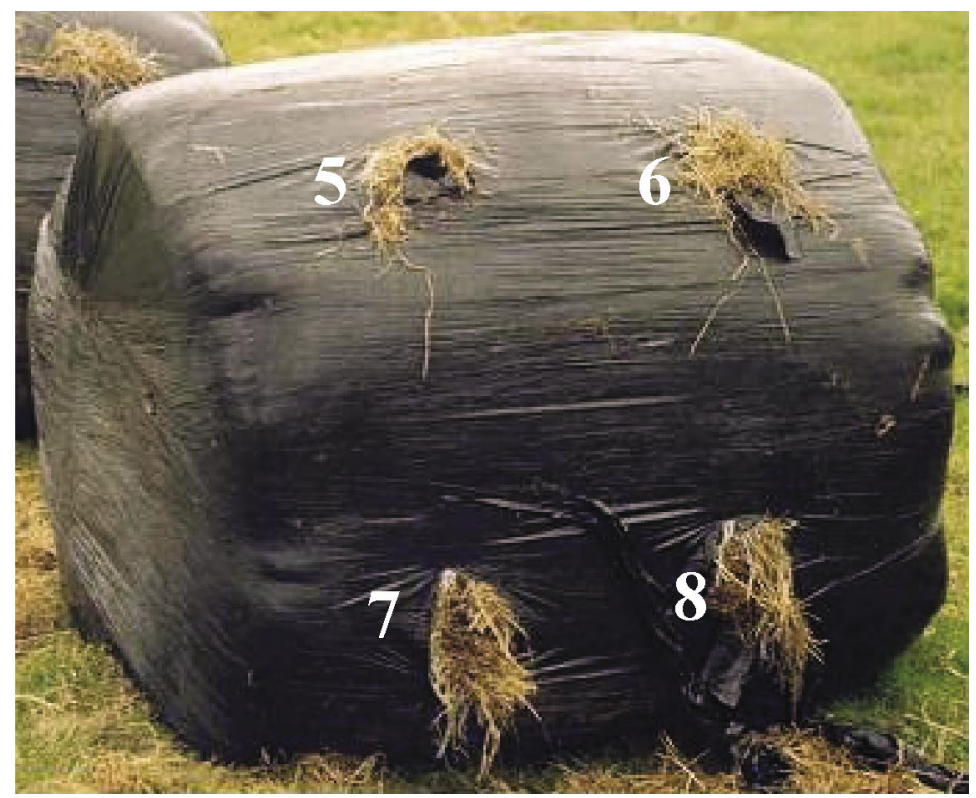

Figure 1. Pre-determined sampling positions on a bale of grass silage from which sample cores were obtained. Sampling positions 1 to 4 were on the opposite side of the bale's barrel (not shown). Bale size $=1.2 \times 1.2 \mathrm{~m}($ diameter $\times$ length $)$ 
(MYSA) as the enumeration medium (Skaar and Stenwig, 1996). Mould and yeast propagules were differentiated based on their colonial features, and were enumerated separately as colony forming units (cfu) per gram wet weight of silage and expressed on a $\log _{10}$ scale. Dry matter (DM) concentration and $\mathrm{pH}$ were determined using silage samples (one $200 \mathrm{~g}$ grab sample per bale) that had no visible fungal growth present. DM was determined by drying $\left(85^{\circ} \mathrm{C}\right.$ for $\left.16 \mathrm{~h}\right)$ in an oven with forced air circulation and $\mathrm{pH}$ was determined using the juice of a silage:distilled water (1:1) mixture.

A nested analysis of variance was completed using SAS, Version 6.12 (SAS Inst. Inc. Cary, NC, USA). The subordinate classification (positions within bales) were nested within the higher level classification (bales) and the variance and significance determined for both components. There were thus ten bales used, eight sampling positions within each bale and two sub-samples at each sampling position.

\section{RESULTS}

The baled silage had 416 (s.d. 67.0) g DM/kg and a $\mathrm{pH}$ of 5.2 (s.d. 0.23). Both mould and yeast propagule numbers varied greatly between and within bales (Table 1). Yeast numbers differed significantly $(\mathrm{P}<0.05)$ both between bales and between core samples from within bales but the variability between

Table 1. Yeast and mould colony forming units (cfu) in baled grass silage

\begin{tabular}{cccccccc}
\hline & \multicolumn{3}{c}{ Yeast $^{1}, \log _{10} \mathrm{cfu} / \mathrm{g}$} & & \multicolumn{3}{c}{ Mould $^{2}, \log _{10} \mathrm{cfu} / \mathrm{g}$} \\
\cline { 1 - 3 } \cline { 6 - 7 } Bale no. & mean $^{3}$ & s.d. & range & & mean $^{3}$ & s.d. & range \\
\hline 1 & $<0.1$ & 0.18 & $0-0.4$ & & $<0.1$ & 0.09 & $0-0.3$ \\
2 & 2.6 & 1.23 & $0-3.6$ & & $<0.1$ & 0.09 & $0-0.3$ \\
3 & 0.6 & 0.57 & $0-1.8$ & & $<0.1$ & 0.09 & $0-0.3$ \\
4 & 2.3 & 0.64 & $1.2-2.8$ & & 0.1 & 0.20 & $0-0.5$ \\
5 & 3.1 & 0.57 & $2.0-3.8$ & & 0 & 0 & 0 \\
6 & 2.8 & 1.84 & $0.3-5.1$ & & 1.4 & 2.23 & $0-6.3$ \\
7 & 3.4 & 1.22 & $1.2-4.7$ & & 1.1 & 1.97 & $0-5.7$ \\
8 & 2.9 & 1.77 & $1.1-6.0$ & & 1.0 & 1.73 & $0-5.2$ \\
9 & 1.8 & 1.75 & $0-4.5$ & & 1.2 & 1.76 & $0.3-5.4$ \\
10 & 2.6 & 1.49 & $0-4.5$ & & 0.5 & 0.87 & $0-4.7$ \\
\hline
\end{tabular}

${ }^{1}$ yeast counts between bales and within bales were significantly different $(\mathrm{P}<0.05)$

${ }^{2}$ mould counts were not subjected to analysis of variance as many bales had few or no moulds

${ }^{3}$ mean of eight core samples per bale (mean of two sub-samples per core sample) 
bales (s.e. $1.44 \log _{10} \mathrm{cfu} / \mathrm{g}$ ) was greater than within the bales (s.e. $0.53 \log _{10} \mathrm{cfu} /$ g). The mould data were not amenable to analysis of variance due to the skewed distribution of values, with many values of zero. The variation in mould and yeast numbers between individual core samples for three representative bales is shown in Figure 2.
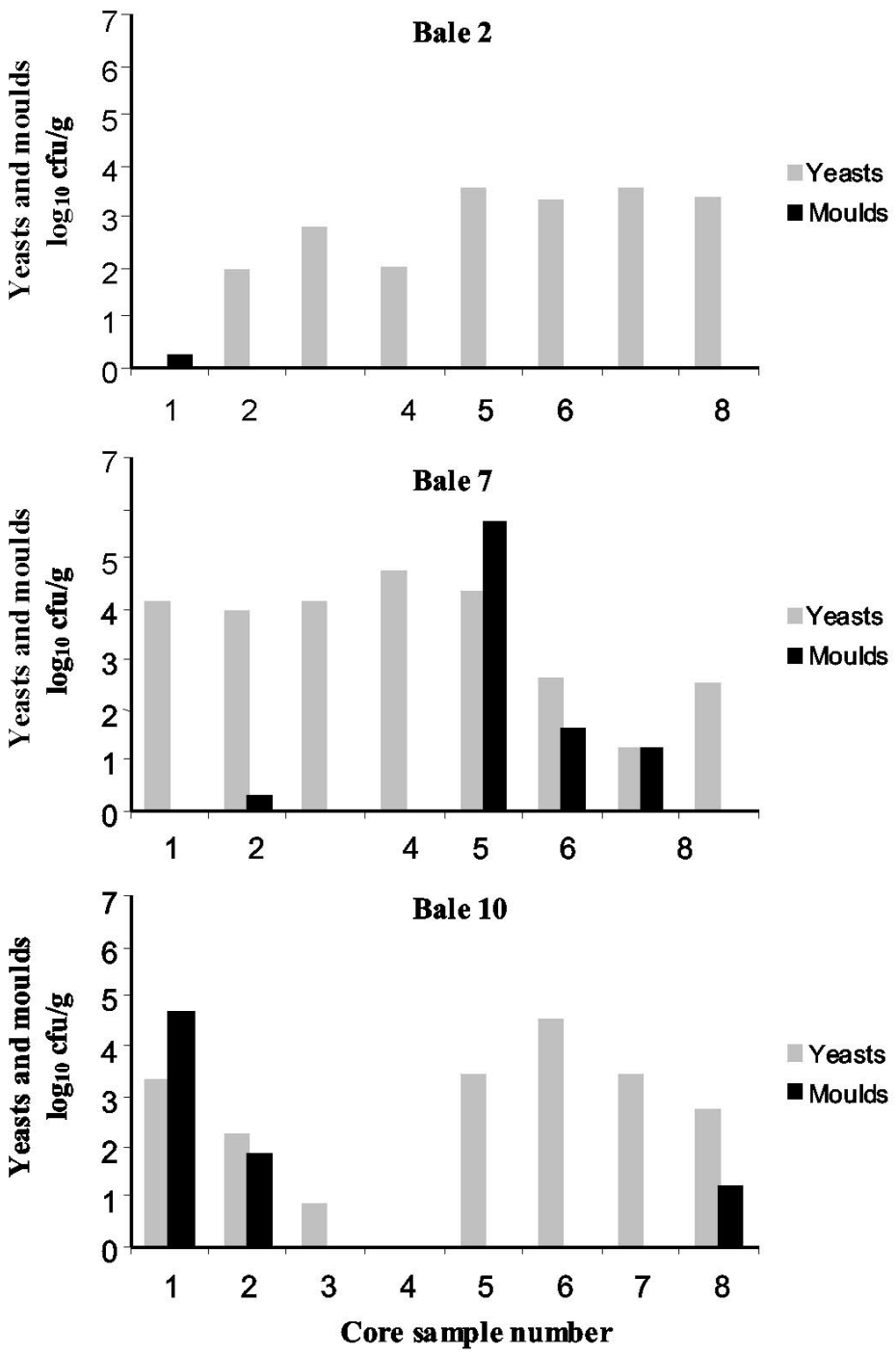

Figure 2. Yeast and mould colony forming units (cfu) in baled grass silage; distribution of mould and yeast propagules in eight core samples from each of three representative bales (of 10 sampled). Each bar represents the mean cfu value of two sub-samples per core sample 


\section{DISCUSSION}

The mean numbers of yeast and mould propagules were relatively low in bales of wilted grass silage that had been wrapped in four layers of plastic stretch-film and stored outdoors for approximately eight months. These bales had been selected for the absence of visible mould and yeast growth, whereas much higher counts have been found in visually non-mouldy parts of baled silage containing visible yeast and mould growth (O'Brien et al., 2006). In that study, high fungal counts were associated with damage to the plastic stretch-film thereby compromising the integrity of the seal and allowing ingress of oxygen during storage.

The results of this study indicate that fungal propagules are heterogeneously distributed throughout bales of silage that contained no visible mould or yeast growth and therefore, there is no consistent pattern of propagule distribution within bales. Accordingly, it is not possible to quantify the fungal spora in a bale on the basis of a single core sample (of the size used) of silage. The sampling protocol used in this investigation involved enumerating yeast and mould propagules in each of eight cores per bale. Mean values of the eight cfu counts for yeasts and moulds were used to obtain what was considered a meaningful estimate of viable propagules in a bale. An alternative approach, involving less culture work, would be to take a number of samples per bale at pre-determined locations (eight was found to be satisfactory and convenient in the present study; Figure 1) and then mix these to produce a representative sample of the outer $20 \mathrm{~cm}$ of the bale. This single composite sample would then be analysed microbiologically, with replication. The foregoing sampling strategy would only be applicable to studies enumerating and identifying fungi in silage free of visible fungal growth; a method to sample visible fungal growth on bales has previously been documented (O'Brien et al., 2005).

\section{CONCLUSIONS}

The numbers of yeast and mould propagules in wilted baled grass silage can be relatively low where ensiling conditions have not limited their growth and development. To overcome the effects of the heterogeneous distribution of fungal propagules in baled silage to be enumerated for moulds and yeasts, it is recommended that eight, or more, samples be taken per bale and these then composited to provide one representative silage sample for microbiological analysis. 


\section{ACKNOWLEDGEMENTS}

The authors are grateful to T. Hegarty and F. Bannon for their statistical advise and to L. Kavanagh for designing and preparing the silage corers. A Teagasc Walsh Fellowship Research Scholarship awarded to M. O’Brien supported this study.

\section{REFERENCES}

Auerbach H., Oldenburg E., Weissbach F., 1998. Incidence of Penicillium roqueforti and roquefortine C in silage. J. Sci. Food Agr. 76, 565-572

Forristal P.D., O'Kiely P., 2003. Sampling procedure with baled silage. In: The Proceedings of the Agriculture Research Forum. Tullamore (Ireland), p. 116

Jonsson A., Lindberg H., Sundås S., Lingvall P., Lindgren S., 1990. Effect of additives on the quality of big-bale silage. Anim. Feed Sci. Tech. 31, 139-155

O’Brien M., O'Kiely P., Forristal P.D., Fuller H.T., 2005. Fungi isolated from contaminated baled grass silage on farms in the Irish Midlands. FEMS Microbiol. Lett. 247, 131-135

O’Brien M., O'Kiely P., Forristal P.D., Fuller H.T., 2006. Quantification and identification of fungal propagules in bales of grass silage produced using standard farm procedures. In: Proceedings of the Agriculture Research Forum. Tullamore (Ireland) (in press)

Seale D.R., Pahlow G., Spoelstra S.F., Lindgren S., Dellaglio F., Lowe J.F., 1990. Methods for the microbiological analysis of silage. In: Proceedings of the EUROBAC Conference, 12-16 August 1986. Grass Forage Rep. 3 Special Issue, 147-164

Skaar I., 1996. Mycological survey and characterisation of the mycobiota of big bale grass silage in Norway. Ph.D. Thesis, Norwegian College of Veterinary Medicine, Oslo, pp. 1-101

Skaar I., Stenwig H., 1996. Malt-yeast extract-sucrose agar, a suitable medium for the enumeration and isolation of fungi in silage. Appl. Environ. Microbiol. 62, 3614-3619

Veldman B., 2003. Effects of dietary mycotoxins on the quality of animal products and on human health. In: The $2^{\text {nd }}$ World Mycotoxin Forum. Noordwijk (The Netherlands), pp. 52-54 